EESTI NSV TEADUSTE AKADEEMIA TOIMETISED. FOOSIKA * MATEMAATIKA ИЗВЕСТИЯ АКАДЕМИИ НАУК ЭСТОНСКОН ССР. ФИЗИКА * МАТЕМАТИКА PROCEEDINGS OF THE ACADEMY OF SCIENCES OF THE ESTONIAN SSR. PHYSICS * MATHEMATICS

$1984,33,1$

\title{
MULTI-FREQUENCY PHOTOCHEMICAL HOLE BURNING IN IMPURITY SPECTRA STUDIED BY TIME DOMAIN DETECTION
}

J. KIKAS, R. KAARLI, A. REBANE. PALJUSAGEDUSLIK FOTOKEEMILINE AUGUPOLETAMINE LISANDISPEKTRITES AJALISE DETEKTEERIMISEGA

Я. КИКАС, Р. КААРЛИ, А. РЕБАНЕ. МНОГОЧАСТОТНОЕ ФОТОХИМИЧЕСКОЕ ВЫЖИГАНИЕ ПРОВАЛОВ В ПРИМЕСНЫХ СПЕҚТРАХ С РЕГИСТРАЦИЕИ ВО ВРЕМЕННОМ ДИАПАउOHE

\section{(Presented by K. K. Rebane)}

A basic limit for the number of holes produced by photochemical hole burning $\left[{ }^{1,2}\right]$ in an inhomogeneously broadened spectral band of impurity absorption (more precisely - in the inhomogeneous distribution function of impurities $\left[{ }^{3}\right]$ ) is given by the ratio of the widths of the inhomogeneous absorption band and the homogeneous absorption line. This ratio reaches values $10^{4} \ldots 10^{5}$ for the purely electronic absorption band of allowed transitions $\left[{ }^{3}\right]$ and is, probably, several orders of magnitude larger for forbidden transitions. In reports on multi-frequency hole burning $\left[{ }^{4}\right]$ the number of holes, however, is of the order of $10^{2}$ or less, i. e. substantially lower than the basic limit. In this paper an essential increase in the number of holes (up to 1600) as well as a new time domain method for" hole detection are reported.

In common experiments on multi-frequency hole burning both burning and recording are performed by scanning the frequency of a narrow band laser source (successive burning). Recently a possibility of burning a. grating of holes in a spectrum by a sequence of mutually coherent light pulses (simultaneous burning) was demonstrated $\left[{ }^{5,6}\right]$. An excitation with an equidistant sequence of mutually coherent light pulses is equivalent to a periodic modulation of the single pulse spectrum and results in the formation of a periodic structure (grating) in the transmission spectrum of the sample owing to photochemical hole burning. Figure, $a$ depicts such a structure for the transmission spectrum of a polystyrene sample activated with $\mathrm{H}_{2}$-tetra-(tret.-butyl)-porphirazine at $1.8 \mathrm{~K}$. Here the burning was performed by a sequence of picosecond light pulses formed by passing a pulse from a synchronously pumped dye laser through a Fabry-Perot interferometer of $12 \mathrm{~mm}(80 \mathrm{ps})$ base. The laser linewidth on recording the spectral grating was of $0.1 \mathrm{~cm}^{-1}$. As demonstrated in $\left[{ }^{6}\right]$ such a spectral grating gives rise to a multipulse response (echo) after pulse excitation.

Figure, $b$ shows the response of a sample whose transmission spectrum was depicted in Figure, $a$. The 20 ps duration of the depicted pulses is determined by the temporal resolution of the synchroscan streak camera. 

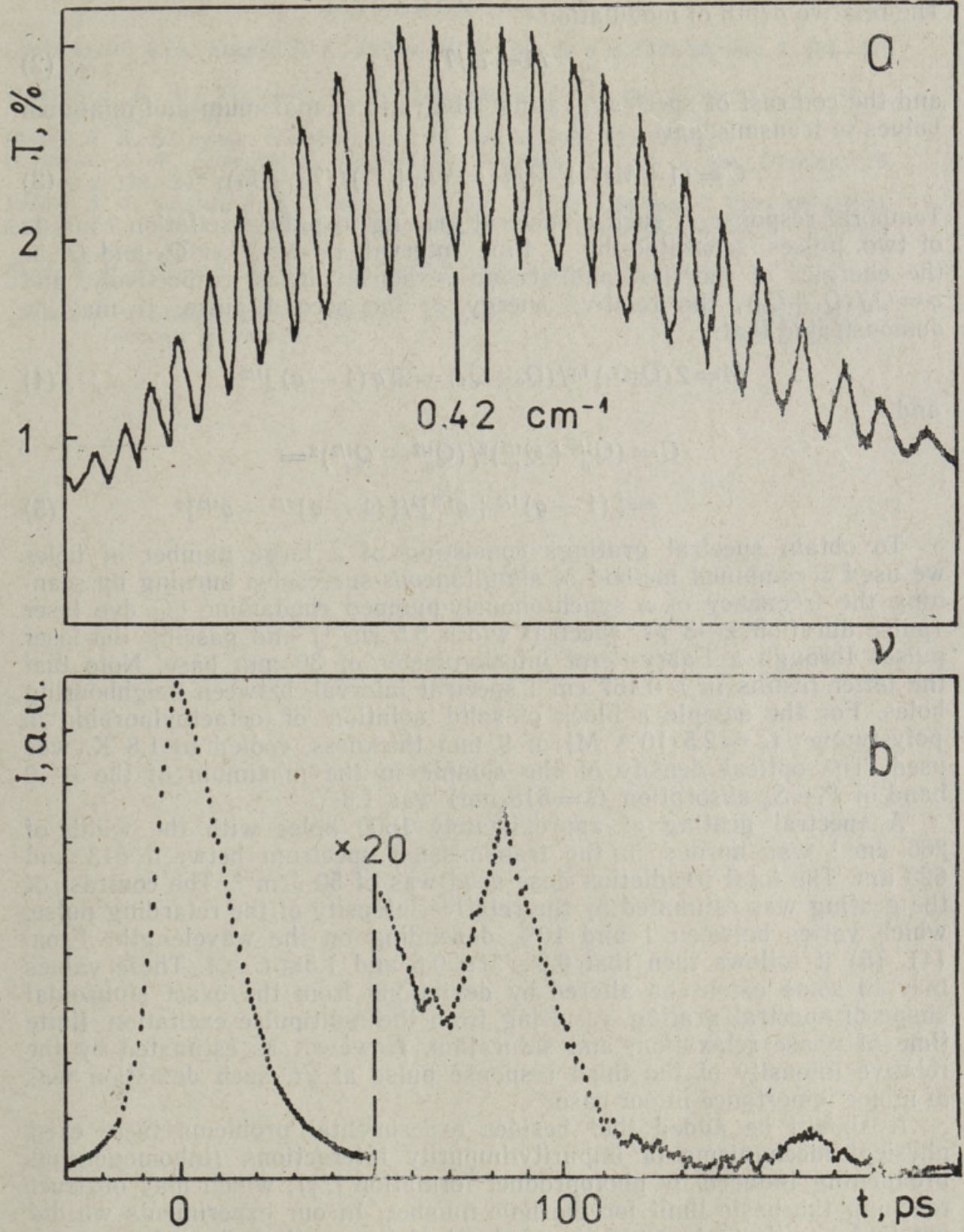

A grating of holes in the transmission spectrum of a polystyrene sample activated with $\mathrm{H}_{2}$-tetra-(tret.-butyl)-porphirazine $(a)$ and the temporal response of the sample to pulse excitation $(b)$.

The contrast of spectral grating can be determined by parameters of temporal response. Let us consider the case of sinusoidal modulation of the transmission spectrum:

$$
T(v)=T_{0}+T_{1} \sin (2 \pi v / \Delta-\varphi) .
$$

Note that such modulation may be formed by burning with pairs of mutually coherent pulses with time delay $\tau=\Delta^{-1}$, when $\tau \ll T_{2}, T_{2}$ being the time of phase relaxation. 
The relative depth of modulation

$$
M=T_{1} / T_{0}
$$

and the contrast of spectral grating (the ratio of maximum and minimum values of transmission)

$$
C=(1+M) /(1-M)=\left(T_{0}+T_{1}\right) /\left(T_{0}-T_{1}\right) .
$$

Temporal response of such a spectral grating to pulse excitation consists of two pulses separated by a time interval $\tau=\Delta^{-1}$. Let $Q_{0}$ and $Q_{1}$ be the energies of the first and second response pulses, respectively, and $q=Q_{1} /\left(Q_{1}+Q_{0}\right)$, the relative energy of the second pulse. It may be demonstrated that

$$
M=2\left(Q_{0} Q_{1}\right)^{1 / 2} /\left(Q_{0}+Q_{1}\right)=2[q(1-q)]^{1 / 2}
$$

and

$$
\begin{aligned}
C & =\left(Q_{0}^{1 / 2}+Q_{1}^{1 / 2}\right)^{2} /\left(Q_{0}^{1 / 2}-Q_{1}^{1 / 2}\right)^{2}= \\
& =\left[(1-q)^{1 / 2}+q^{1 / 2}\right]^{2} /\left[(1-q)^{1 / 2}-q^{1 / 2}\right]^{2} .
\end{aligned}
$$

To obtain spectral gratings consisting of a large number of holes we used a combined method of simultaneous-successive burning by scanning the frequency of a synchronously-pumped rhodamine $6 \mathrm{G}$ dye laser (pulse duration $2-3 \mathrm{ps}$, spectral width $5.5 \mathrm{~cm}^{-1}$ ) and passing the laser pulses through a Fabry-Perot interferometer of $30 \mathrm{~mm}$ base. Note that the latter results in a $0.167 \mathrm{~cm}^{-1}$ spectral interval between neighbouring holes. For the sample a block of solid solution of octaethylporphin in polystyrene $\left(c=2.5 \cdot 10^{-4} \mathrm{M}\right)$ of $9 \mathrm{~mm}$ thickness, cooled to $1.8 \mathrm{~K}$, was used. The optical density of the sample in the maximum of the $0-0$ band of $S_{1} \leftarrow S_{0}$ absorption $(\lambda=618 \mathrm{~nm})$ was 1.8 .

A spectral grating of approximately 1600 holes with the width of $266 \mathrm{~cm}^{-1}$ was burned in the transmission spectrum between 613 and $623 \mathrm{~nm}$. The total irradiation dose used was of $50 \mathrm{Jcm}^{-2}$. The contrast of the grating was estimated by the relative intensity of the retarding pulse, which varies between 1 and $10 \%$ depending on the wavelength. From (4), (5) it follows then that $0.2 \leqslant M \leqslant 0.6$ and $1.5 \leqslant C \leqslant 4$. These values may to some extent be altered by deviations from the exact sinusoidal shape of spectral grating, resulting from the multipulse excitation, finite time of phase relaxation, and saturation. However, as estimated by the relative intensity of the third response pulse at $2 \tau$, such deviation was of minor importance in our case.

It should be added that besides experimental problems there exist physical mechanisms of impurity-impurity interactions (inhomogeneous broadening induced by photoproduct formation $\left[{ }^{7}\right]$ ), which may obstruct reaching the basic limit for the hole number. In our experiments we did not find any dependence of the contrast of the grating at a given wavelength on the spectral width of the grating, i. e. on the number of burned out impurities. This proves that in our case the photoproduct-induced inhomogeneous broadening is negligible. This result is of essential importance for practical applications of photochemical hole burning $\left[{ }^{7}\right]$.

The authors are indebted to K. K. Rebane and P. Saari for discussion and useful remarks. Thanks are due to A. Anijalg for experimental assistance, to V. N. Kopranenkov and A. F. Mironov for synthesizing activators, and to I. V. Bitov for sample preparation. 


\section{REF E R E N E S}

1. Гороховский А. А., Каарли Р. К., Ребане Л. А. Письма в ЖЭТФ, 20, вып. 7, 474-479 (1974).

2. Kharlamov, B. M., Personov, R. I., Bykovskaya, L. A. Opt. Commun., 12, № 1, $191-193$ (1974).

3. Ребане К. К. Ж. прикл. спектроскопии, 37, вып. 6, 906-922 (1982).

4. Gutierrez, A. R., Friedrich, J., Haarer, D., Wolfrum, H. IBM J. Res. Develop., 26, № 2, 198-208 (1982).

5. Ребане А. К., Каарли Р. К., Саари П. М. Опт. и спектр. 55, вып. 7, 320-323 (1983).

6. Rebane, A., Kaarli, R., Saari, P., Anijalg, A., Timpmann, K. Opt Commun. 47. № 3. 173-176 (1983).

7. Кикас Я. В., Ребане К. К. Изв. АН ЭстССР. Физ. Матем. (in press).

Academy of Sciences of the Estonian SSR, Institute of Physics
Received

Oct. 6, 1983 